\title{
DOR NO JOELHO APÓS ARTROPLASTIA TOTAL - UMA ABORDAGEM SISTEMATIZADA
}

\section{PAIN FOLLOWING TOTAL KNEE ARTHROPLASTY - A SYSTEMATIC APPROACH}

Wilson Mello Alves Júnior ${ }^{1}$, Eduardo Zaniol Migon², Jose Luis Amim Zabeu ${ }^{3}$

\section{RESUMO}

A artroplastia total de joelho (ATJ) é um procedimento reconhecidamente bem sucedido. $\mathrm{O}$ envelhecimento da população e a crescente demanda de qualidade de vida têm aumentado muito a indicação do procedimento. Entretanto, a ATJ apresenta algumas complicações que ainda carecem de uma resolução definitiva. A dor após a ATJ ocorre por uma miríade de causas, as quais devem ser sistematicamente pesquisadas a fim de se obter um diagnóstico e tratamento corretos. História, exame físico, exames laboratoriais e de imagens devem todos ser incluídos nessa propedêutica e repetidos até que uma razão plausível seja apontada, já que a indicação de revisão apenas pela dor pode ter resultados catastróficos.

Descritores - Artroplastia total do joelho; Diagnóstico

\section{ABSTRACT}

Total knee arthroplasty (TKA) is known for being a successful procedure. The aging of the population and the growing demand for quality of life have greatly increased indication for the procedure. Nonetheless, TKA presents some complications that still lack definitive resolutions. Painful TKA is caused by a myriad of reasons that should be systematically studied to arrive at a correct diagnosis and treatment. History, physical examination, laboratory and image exams must all be included in the workup and repeated until a plausible reason is identified, since pain as the only indication for TKA revision may have catastrophic results.

Keywords - Arthroplasty, Replacement, Knee; Diagnosis

\section{INTRODUÇÃO}

A artroplastia total do joelho (ATJ) é uma operação de grande sucesso no tratamento das alterações degenerativas do joelho e apresenta uma demanda crescente em todo o mundo, devido ao envelhecimento da população e à necessidade de preservar qualidade de vida das pessoas. Entretanto, uma em cada 300 artroplastias do joelho terão dor sem uma explicação conhecida ${ }^{(1)}$. A dor pode ser em repouso ou com movimento. O joelho pode ter um arco de movimento bom, uma avaliação objetiva perfeita da prótese, com as radiografia mostrando boa posição dos implantes, porém com o paciente queixando-se de dor. A avaliação adequada deste quadro é importante para o ortopedista que realiza a ATJ. É importante lembrar que a indicação da revisão da ATJ sem um diagnóstico preciso será bem sucedida em apenas $17 \%$ dos casos e que, mesmo se alguma alteração for encontrada e corrigida no transoperatório, a revisão somente terá bons resultados em $25 \%$ dos $\operatorname{casos}^{(2)}$. A avaliação de uma prótese total dolorosa deve envolver quatro pontos importantes a fim de se identificar a etiologia precisa: avaliação clínica, investigação laboratorial, avaliação por imagens e análise microbiológica. Mesmo quando todas estas etapas são realizadas, nem sempre conseguimos chegar a um diagnóstico. Por isso, é importante determinarmos uma abordagem sistematizada que permita repetir o processo diagnóstico até uma conclusão adequada e só então indicarmos o tratamento.

\section{Causas da dor na ATJ}

O primeiro ponto a ser avaliado é a provável origem da dor. Para facilitar a pesquisa, dividem-se as possíveis

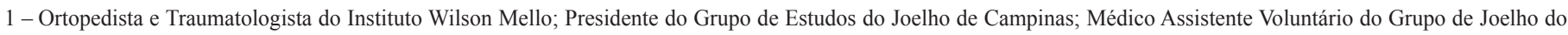
Serviço de Ortopedia da PUC Campinas, Serviço de Ortopedia do Centro Médico de Campinas, SP.

2 - Ortopedista e Traumatologista, Residente do $4^{\circ}$. ano em Cirurgia de Joelho da PUC de Campinas e Instituto Wilson Mello, Campinas, SP.

3 - Ortopedista e Traumatologista do Instituto Wilson Mello; Chefe do Serviço de Ortopedia PUC Campinas, SP.

Trabalho realizado no Instituto Wilson Mello, Campinas, SP.

Correspondência: Av. Jose Rocha Bonfim, 214, 1ª a, Cond.Praça Capital - Edifício Chicago, CEP 13056240 - Campinas SP. E-mail: wmelloa@me.com 
causas em articulares e não articulares. Abaixo listamos os dois grupos.

\section{Causas articulares}
a. Soltura do implante
b. Instabilidade
c. Falha de um componente
d. Infecção
e. Problemas femoropatelares
f. Pinçamento sinovial
g. Osteólise: sinovite ou microfratura
h. Outras causas:
1 - Patellar clunk syndrome
2 - Irritação da faceta lateral da patela
3 - Disfunção do tendão do músculo poplíteo
4 - Componente tibial saliente no lado medial

\section{Causas não articulares}
a. Patologia neurológica
b. Doença no quadril: osteoartrose, necrose avascu- lar, fratura por insuficiência do osso subcondral na cabeça do fêmur
c. Doença vascular: insuficiência arterial, aneurisma, trombose
d. Distrofia simpático reflexa
e. Irritação de tecidos moles: tendinite, bursite, neu- roma
f. Outras doenças: doença de Paget, sinovite vilono- dular pigmentada, artrite reumatoide e doenças do tornozelo e pé
f. Fatores psicológicos

\section{Avaliação do paciente com dor após ATJ}

1 - História clínica e exame físico

2 - Avaliação laboratorial

3 - Avaliação por imagens

\section{HISTÓRIA CLÍNICA}

A história da dor é da maior relevância na investigação. Para facilitar a investigação, recomenda-se seguir um roteiro na história da dor:

1 - Localização e irradiação da dor: a palpação das estruturas periarticulares é importante para identificar neuromas, problemas com o tamanho e implantação da prótese.

2 - Tempo de duração dos sintomas: o tipo de dor comparada à dor pré-operatória contém informações importantes. Se a dor é igual à inicial, é mais provável que a causa seja extra-articular e, por isso, a artroplastia não resolveu os sintomas. As patologias do quadril tais como a necrose avascular da cabeça do fêmur, a osteoartrose e a fratura por insuficiência do osso subcondral podem provocar sintomas no joelho por irritação do nervo obturador. Problemas vasculares, tais como a insuficiência arterial com claudicação intermitente, o aneurisma arterial e a trombose são causas de dor no joelho. História de diabetes com a presença neuropatia periférica pode causar dor nos membros inferiores associada a parestesias. Pacientes com história de diabetes, psoríase, artrite reumatoide ou de outras que geram imunodepressão são mais propensas a desenvolver infecção.

3 - Quando a dor aparece: pacientes com dor persistente desde o pós-operatório imediato sem história de melhora devem ser investigados à procura de infecção aguda, instabilidade da prótese, mau alinhamento e causas não articulares. Nos pacientes em que houve uma melhora substancial da dor no pós-operatório e que evoluem com dor posteriormente, a causa da dor pode ser decorrente de soltura dos componentes, de instabilidade posterior tardia (pacientes com próteses que preservaram o ligamento cruzado posterior e com instabilidade tardia) ou de infecção tardia por via hematogênica ${ }^{(3)}$.

4 - Fatores de melhora: o relato da dor que aparece com movimento e melhora com repouso sugere origem mecânica, compatível com soltura de componentes ou com patologia degenerativa no quadril. Dor contínua aponta para a suspeita de problemas inflamatórios, sendo o mais importante a infecção.

5 - Incapacidade provocada pela dor: definir o grau de incapacidade também é um parâmetro importante na definição da causa da dor. Pacientes que necessitam de algum tipo de suporte para caminhar, tais como muletas ou cadeiras de roda, provavelmente apresentam causas mecânicas, tais como instabilidade ou soltura de componentes. Quando não há correlação entre função e a intensidade da dor, o médico deve suspeitar de distrofia simpático reflexa.

\section{Exame físico}

O exame físico é geral, com ênfase no alinhamento do membro, no arco de movimento, na presença de edema articular ou periarticular, palpação da articulação femoropatelar e o tipo de marcha (Figura 1). A presença da tétrade calor, rubor, tumor e dor faz pensar em um quadro inflamatório agudo, devendo a infecção ser 
considerada como a primeira hipótese diagnóstica. Entretanto, essa condição mais explícita de infecção não é o quadro mais frequente. O grande problema são as infecções com poucas manifestações clínicas, notadamente apenas dor.

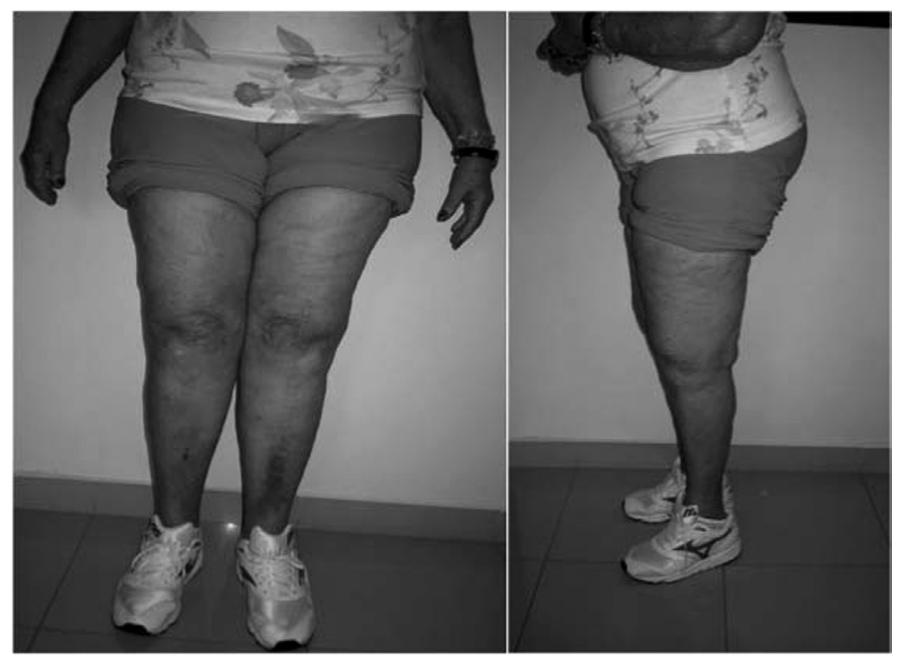

Figura 1 - ATJ bilateral mostrando alinhamento adequado e extensão completa.

O mau alinhamento do membro indica problemas com o alinhamento do implante, que poderá ser confirmado com os exames de imagem. A suspeita clínica direciona o exame radiológico. $\mathrm{O}$ ângulo entre a tuberosidade anterior da tíbia e o maior eixo do pé são indicativos de problemas de alinhamento rotacional do componente tibial.

O exame da marcha é fundamental para demonstrar eventual instabilidade. A assimetria da rotação dos pés indica que o componente tibial foi implantado com rotação interna ou externa demasiada, o que pode ser confirmado com uma tomografia computadorizada ${ }^{(3)}$.

A palpação de pontos dolorosos periarticulares ajuda a identificar neuromas de cicatriz ${ }^{(4)}$, tendinites e bursites, como as que ocorrem na pata de ganso ${ }^{(5)}$ ou no bíceps femoral $^{(6)}$. A infiltração com anestésicos locais é um método simples para definir essas causas de dor. Dor na interlinha, especialmente na medial, pode ser provocada pelo componente tibial saliente (Figura 2).

A amplitude de movimento passiva e ativa deve ser analisada na busca de eventuais perdas. A atitude em flexo pode ser secundária a um erro no ato cirúrgico (espaço em extensão tenso), a um derrame articular ou até mesmo à ruptura do aparelho extensor (lesão do tendão do quadríceps, do ligamento patelar ou fratura da patela). O déficit de flexão ocorre geralmente no pós-operatório de artroplastias que preser-

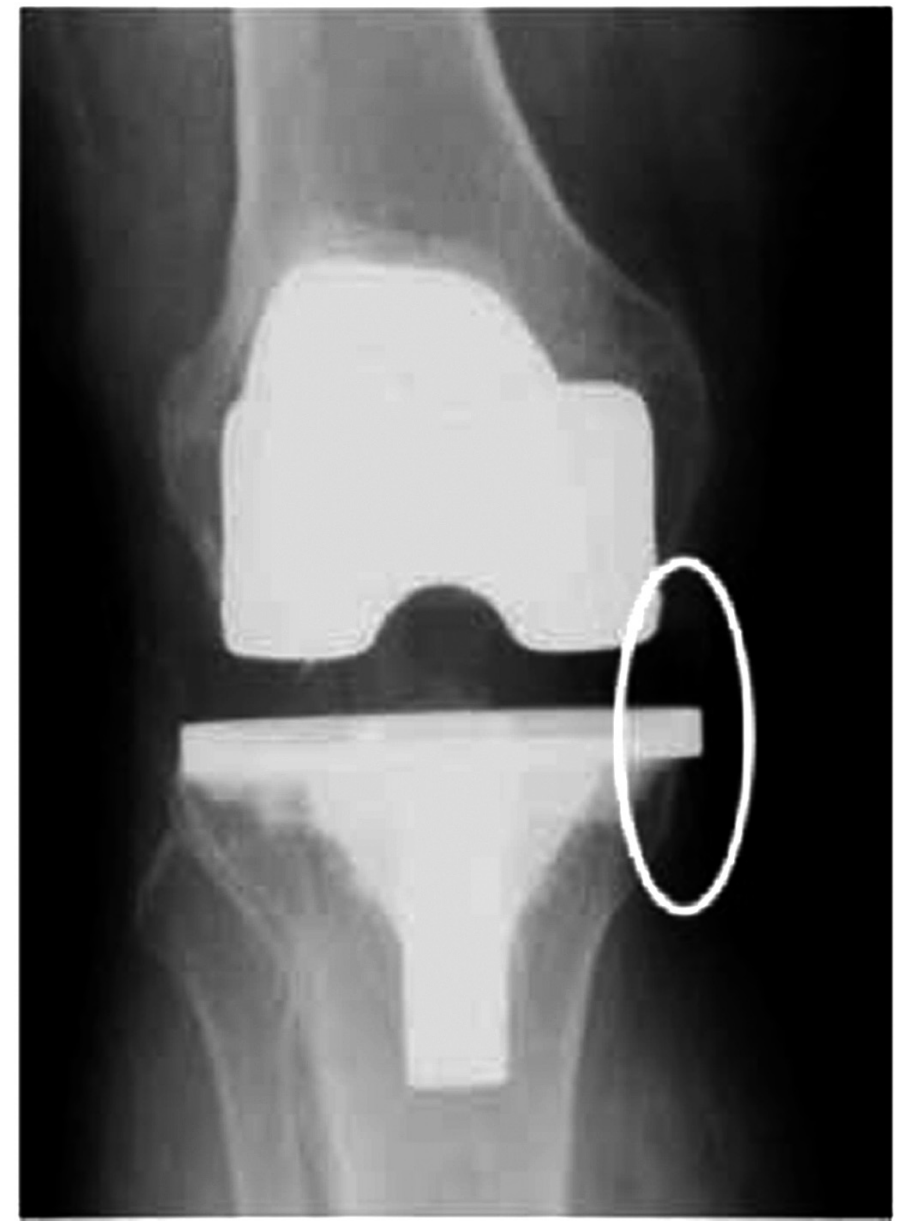

Figura 2 - Componente tibial saliente no compartimento medial.

vam o ligamento cruzado posterior em que o mesmo apresenta tensão excessiva.

O exame da articulação femoropatelar pode evidenciar eventual desalinhamento ou instabilidade. Avaliação do músculo quadríceps e do mecanismo extensor é importante na função articular e na gênese de dor. A instabilidade femoropatelar pode ser causada por um componente femoral em rotação interna, por um componente tibial em demasiada rotação interna ${ }^{(7)}$ ou por um alinhamento em valgo excessivo do joelho. A demonstração do desalinhamento rotacional é difícil com radiografias simples, sendo muitas vezes necessário lançar mão de uma tomografia computadorizada ${ }^{(8)}$.

A avaliação do estado vascular e neurológico é fundamental para afastar os problemas de dor referida por compressão radicular, neurite periférica e por insuficiência vascular.

Quando a dor é desproporcional à função, devemos considerar o diagnóstico de distrofia simpático reflexa, a qual apresenta uma incidência de $0,8 \%$ no pós-operatório da artroplastia total do joelho ${ }^{(9)}$. Os quatro sinais 
mais comuns dessa patologia são: dor, edema, rigidez articular e alteração do brilho e textura da pele. A dor é o sintoma mais facilmente notado. É uma dor difusa do tipo queimação ou picada a qual piora com movimento e com o frio. O paciente não consegue indicar a sede da dor. A rigidez articular aparece por causa da dor provocada pelo movimento. O diagnóstico precoce e a pronta instituição do tratamento são fundamentais para a melhora dos pacientes, já que $50 \%$ deles evoluem para dor crônica ${ }^{(10)}$.

Finalmente, o diagnóstico de infecção requer que o ortopedista "pense" nessa possibilidade. A infecção aguda com grande edema e drenagem é facilmente diagnosticada. No entanto, as infecções crônicas de baixa virulência são as mais comuns e provocam dor persistente com ou sem aumento de volume da articulação, especialmente se causadas por germes anaeróbicos. Portanto, o diagnóstico de infecção sempre deve estar presente na mente do médico ao avaliar um joelho com dor após a ATJ.

\section{Avaliação laboratorial}

Os exames de laboratório servem para ajudar na definição da presença de infecção. O hemograma, especificamente o leucograma, raramente estará afetado nas próteses com infecção crônica. Provas de atividade inflamatória são mais sensíveis na identificação de um joelho infectado. A velocidade de hemossedimentação (VHS) e a proteína C reativa (PCR) são os exames mais usados para comprovar a suspeita de infecção. No entanto, por serem testes de triagem, apresentam elevada sensibilidade e alto número de falsos positivos, como nos casos de doença inflamatória sistêmica. A presença de VHS e PCR persistentemente aumentados eleva muito a suspeição da presença de infecção articular.

Sabe-se que o VHS permanece elevado por três a seis meses após a cirurgia. O VHS médio nos pacientes com infecção é de $57 \mathrm{~mm} / \mathrm{h}$, enquanto que nos joelhos assépticos este valor médio está em $27 \mathrm{~mm} / \mathrm{h}$. Assim, se o VHS está acima de $30 \mathrm{~mm} / \mathrm{h}$ teremos alta suspeita de infecção com sensitividade de $80 \%$, especificidade de $62,5 \%$, valor preditivo positivo de $47,1 \%$ e valor preditivo negativo de $88,2 \%$.

A proteína $\mathrm{C}$ reativa ( $\mathrm{PCR}$ ) estará aumentada por três a quatro semanas após a cirurgia. A persistência da PCR aumenta por mais de quatro semanas, em conjunto com VHS aumentado é um forte indicador de presença de infecção. A sensibilidade e especificidade são similares à do VHS.
O próximo passo na investigação de uma suspeita de infecção é a punção articular. Mason et al ${ }^{(11)}$ demonstraram que na realização de punções em 86 em joelhos com artroplastia, sendo 31 com sinais de soltura séptica e 55 com sinais de soltura asséptica, a contagem celular foi de grande valor. A presença de 2.500 leucócitos por alto campo, com predominância de $60 \%$ de polimorfonucleares (PMN) foi altamente indicativo de presença de infecção, com uma sensitividade de $98 \%$ e especificidade de $98 \%$.

Devemos adotar todos os cuidados na punção para evitar contaminação e falsos positivos. Nem sempre é possível obter um aspirado articular, especialmente nos joelhos sem hidartrose. É importante frisar que o paciente não deve fazer uso de antibióticos e utilizar anestésico local apenas na pele e não intra-articular. $\mathrm{O}$ material deve ser enviado imediatamente ao laboratório ou ser semeado em meio de transporte enriquecido no momento da punção ${ }^{(12)}$.

\section{Avaliação por imagens}

1 - Radiografias simples: são importantes na avaliação da posição dos componentes e a presença de linhas de radioluscência, que podem ser indicativos de soltura dos componentes (Figura 3).

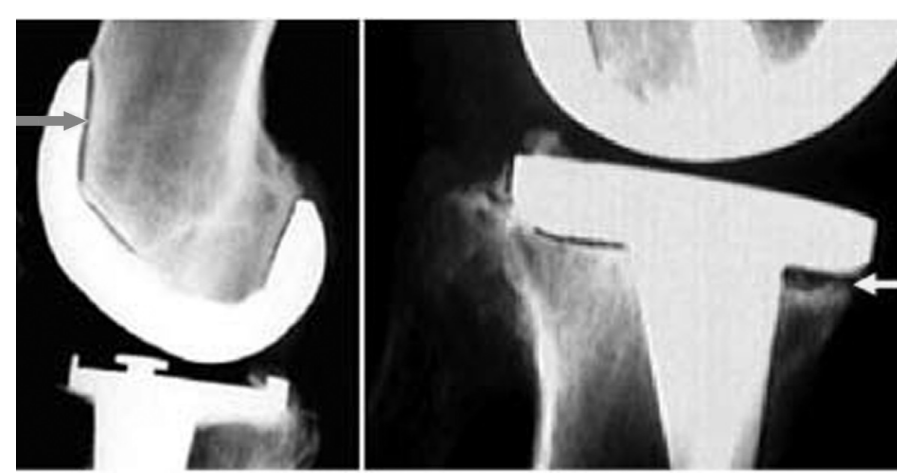

Figura 3 - Linhas de radioluscência no fêmur e tíbia (setas).

A incidência em anteroposterior (AP) permite a avaliação do alinhamento em varo ou valgo dos componentes, eventual rotação dos mesmos e a posição da linha articular. A presença de reação periosteal, de gás nas partes moles e de sinais de soltura precoce dos implantes direciona o diagnóstico para infecção. A incidência em perfil (P) documenta a inclinação posterior da tíbia, a altura da patela relativa à linha articular, a posição relativa do fêmur sobre a tíbia permitindo a identificação da falência do ligamento cruzado posterior (Figura 4). 


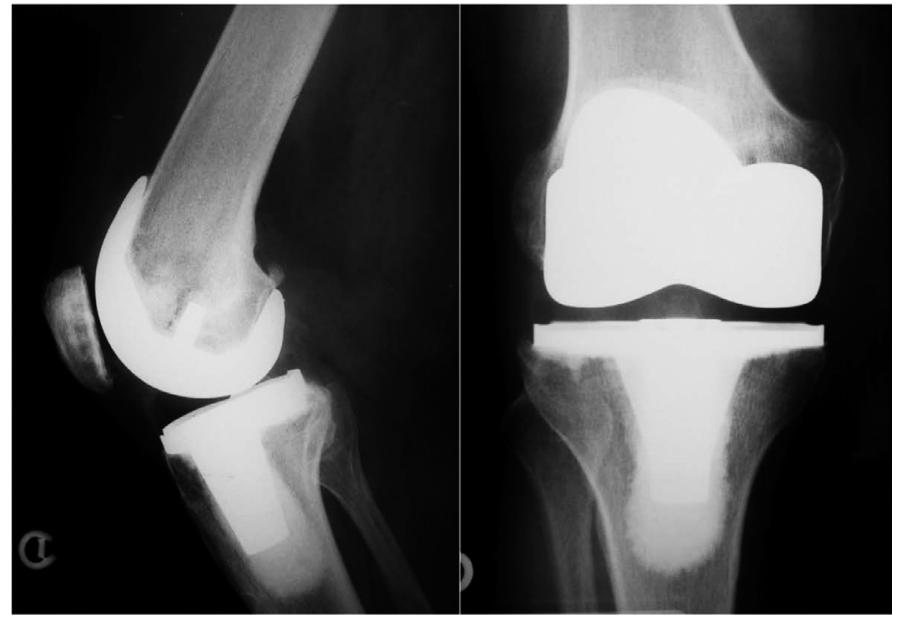

Figura 4 - Controle pós-operatório de ATJ: avaliação do tamanho e posição dos componentes.

O estudo radiográfico em axial da patela demonstra a posição da patela em relação ao fêmur, documentando defeitos de rotação do componente femoral e a luxação da patela (Figura 5).

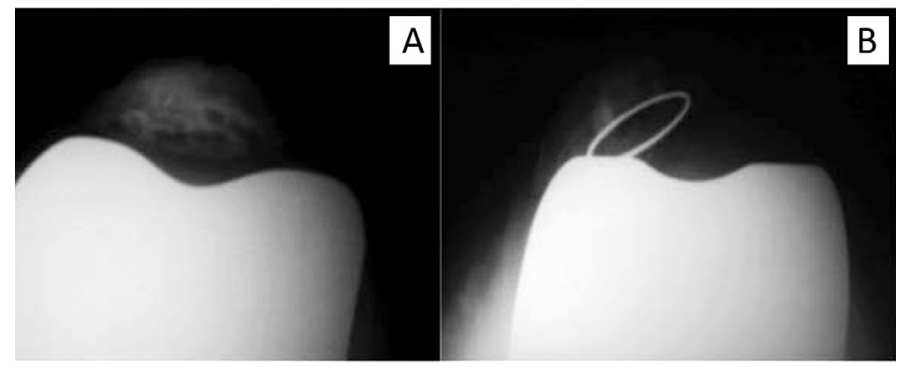

Figura 5 - Axial de patela com bom posicionamento $(A)$ e com patela subluxada (B).

As radiografias panorâmicas dos membros inferiores são importantes para avaliação do alinhamento do implante em relação ao eixo mecânico do membro (Figura 6).

Nessa fase da investigação, é importante ao cirurgião ter acesso às radiografias pré-operatórias que definem a patologia inicial do joelho. A análise sequencial das radiografias é fundamental para avaliação da evolução das linhas de radioluscência e das áreas osteólise. Pequenas áreas de radioluscência não são incomuns em pacientes assintomáticos e, por isso, é conveniente sempre ver a primeira, a penúltima e a última radiografia. Assim, é mais fácil documentar o aparecimento ou o aumento de linhas suspeitas de soltura de modo retrospectivo por um longo período.

As radiografias do quadril poderão demonstrar a presença de coxartrose (especialmente as mediais), de fratura por insuficiência subcapital e de necrose avascular, todas fontes de dor no joelho.

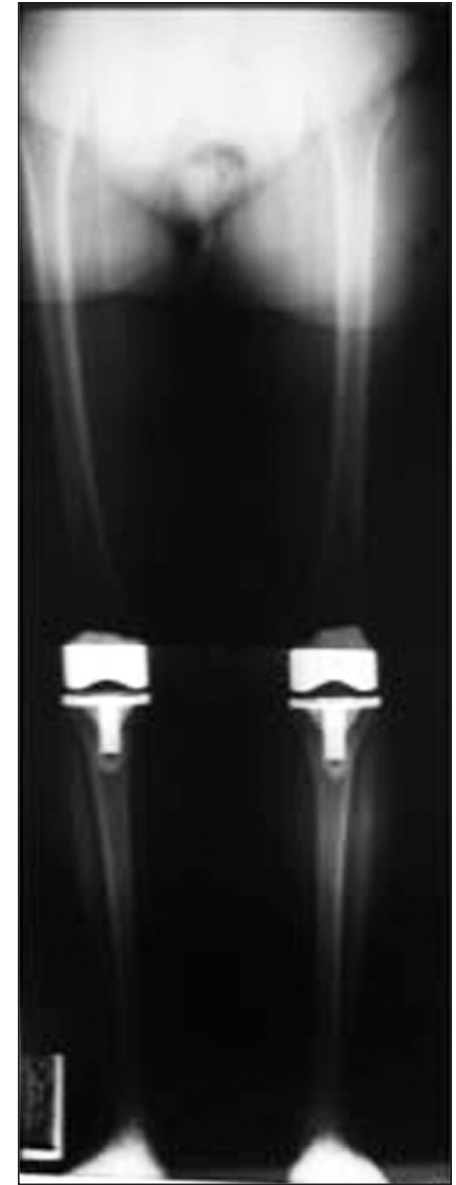

Figura 6 - Estudo radiográfico panorâmico dos membros inferiores demonstrando ATJ bilateral com restituição do eixo mecânico normal.

2 - Artrografia: pode ter valor no diagnóstico de soltura de componentes, especialmente do componente tibial, onde é mais fácil ver a presença de contraste na interface cimento - prótese ou cimento - osso. Porém, não é um exame usado rotineiramente. Por ser um exame radiológico muito pouco popular no presente, raramente se conseguem imagens adequadas. Outro problema importante é o risco de contaminação durante a punção articular.

3 - Cintilografia: pode demonstrar hipercaptação ao redor dos implantes por muitos anos após uma artroplastia bem sucedida ${ }^{(13)}$. O marcador inicial a ser utilizado é o Tecnécio-99m, o qual apresenta alta sensibilidade para demonstrar soltura, mas baixa especificidade. A soltura deve ser suspeitada quando há uma captação difusa, aumentada, desproporcional e que aumenta quando exames seriados são comparados. No entanto, mesmo se as características citadas estiverem presentes, é impossível diferenciar a soltura asséptica da soltura séptica. $\mathrm{O}$ principal valor desse exame reside na sua normalidade, quando a soltura pode ser descartada ${ }^{(14)}$. O uso da cin- 
tilografia com leucócitos marcados com Índio-111 deve ter interpretação semelhante ao da com uso de tecnécio quando isolada. Porém, a comparação dos dois métodos acrescenta informações úteis, de modo que resultados divergentes falam a favor de infecção, com sensibilidade e especificidade de aproximadamente $85 \%{ }^{(15)}$. No entanto, na prática não é utilizada de rotina.

4 - Ultrassonografia (US): a US pode detectar alterações nas partes moles superficiais, incluindo o tendão do quadríceps, o ligamento patelar e o colateral medial, apresentando sensibilidade maior que a ressonância magnética no pós-operatório da artroplastia de joelho ${ }^{(16)}$. Além disso, esse exame tem uma boa correlação com as radiografias no diagnóstico de desgaste do polietileno ${ }^{(17)}$ e é uma ferramenta útil para guiar punções de coleções periprotéticas $^{(18)}$. Considerar que esse é um exame dependente do operador, por isso o seu resultado deve sempre ser analisado de forma criteriosa.

5 - Tomografia computadorizada (TC): a TC tem indicações precisas na avaliação desses pacientes. Esse exame pode ser solicitado para descrever com maior acurácia áreas de osteólise ${ }^{(18)}$ ou em suspeita de fraturas periprotéticas; no entanto, talvez o seu maior valor esteja na determinação da rotação dos implantes.

6-Ressonância magnética (RM): a RM sofre influência direta dos artefatos metálicos, principalmente aqueles com morfologia irregular e feitos de aço inoxidável. Alterações nos protocolos de aquisição das imagens podem diminuir o efeito dos artefatos e demonstrar alterações como osteólise, lesão de partes moles e fraturas por insuficiência ${ }^{(18)}$. Entretanto, esse exame não é rotineiramente usado no nosso meio para esse tipo de investigação.

\section{CAUSAS ARTICULARES DE DOR APÓS ATJ}

As causas mais importantes a serem pesquisadas são a infecção e a soltura dos componentes. O diagnóstico destas patologias foi discutido acima: com uma história clínica que pode ser característica, exame físico cuidadoso, o uso de exames de laboratório, especialmente hemograma, VHS e PCR, e análise criteriosa das radiografias iniciais e a evolução das imagens radiográficas, é possível chegar a uma conclusão definitiva da causa da dor.

\section{1 - Instabilidade articular após artroplastia:}

É uma das causas mais comuns nas artroplastias dolorosas e nas próteses de joelho com mais de cinco anos é a causa mais frequente revisão ${ }^{(18)}$. Pode ser uma instabilidade no plano frontal, no sagital ou no axial. No plano frontal, encontramos as instabilidades por falência do ligamento colateral medial ou lateral, a qual pode ser documentada com radiografias em stress (Figuras 7A, 7B e 8). Da mesma forma, a falência do ligamento cruzado posterior, nos pacientes em que a prótese inicial preservou esse ligamento, gera uma posteriorização da tíbia em relação ao fêmur, que pode ou não ser sintomática (Figura 7C). A instabilidade no eixo axial é

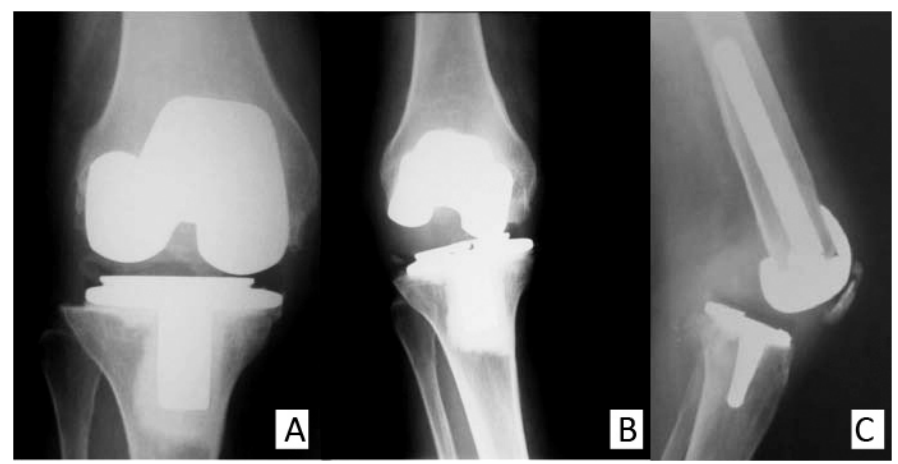

Figura 7 - Instabilidade lateral $(A$ e $B)$ e instabilidade posterior.

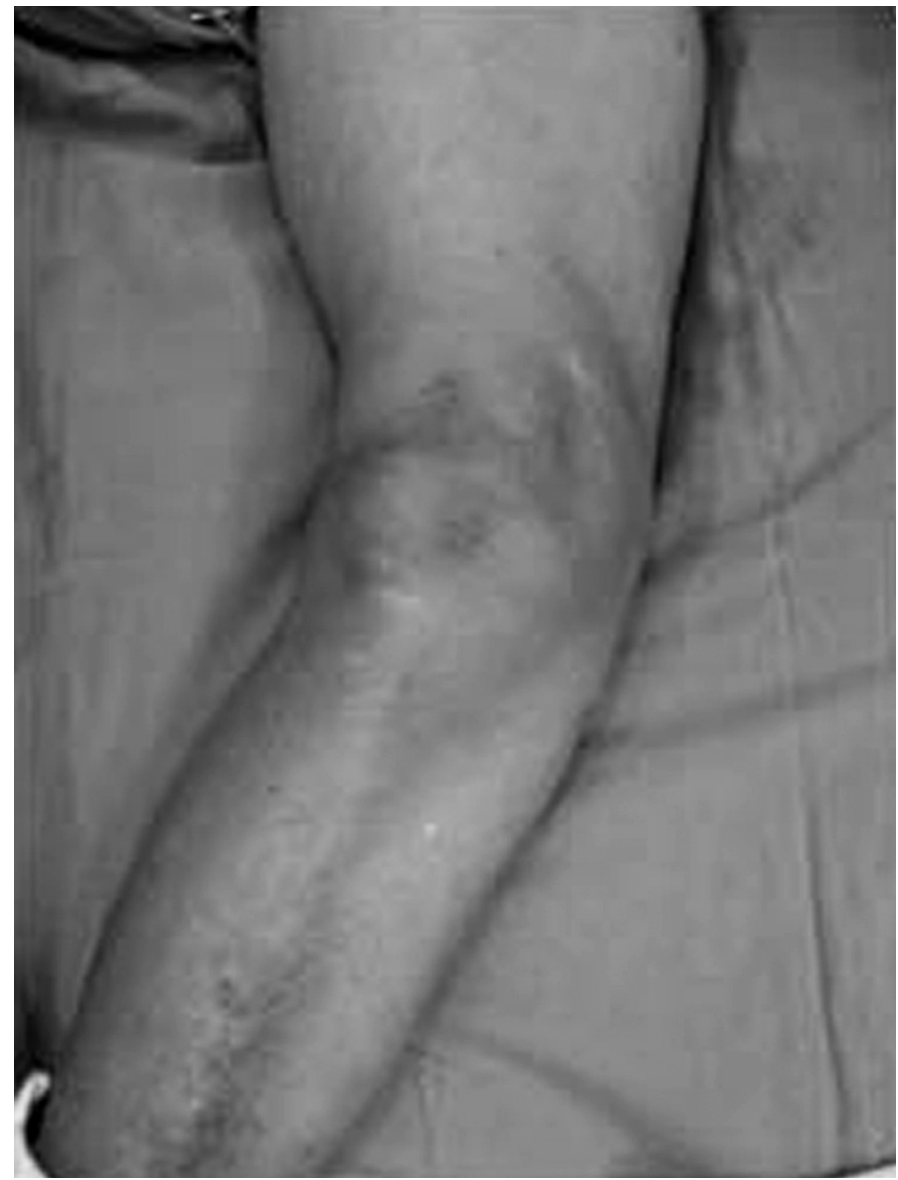

Figura 8 - Instabilidade no plano coronal causada por falência do ligamento colateral medial. 
mais dificil de ser diagnosticada. Ocorre um pistonamento da perna sob o fêmur quando o paciente está sentado na mesa de exame com o joelho fletido. Ela é causada por um espaço de flexão aumentado. É uma instabilidade sutil, que pode apresentar-se com flexo do joelho por falta de espaço na extensão. O diagnóstico é mais difícil, pois a artrofibrose é a hipótese diagnóstica inicial pela falta da extensão completa. A maioria destes casos acontece nos implantes que preservam o ligamento cruzado posterior. Segundo Firestone e Eberle, $80 \%$ destes pacientes revela que nunca sentiu o joelho normal, 55\% deles tinham história de falseio articular e $73 \%$ melhorava com uso de uma órtese. Hidrartrose aos esforços era uma queixa comum a todos os pacientes, sendo que $73 \%$ deles referiam melhora do derrame com o repouso ${ }^{(19)}$. Nos casos de dúvida no diagnóstico, o uso de um brace para estabilização do joelho pode ajudar o esclarecimento da causa da dor: quando ocorre melhora dos sintomas, a causa provável é a instabilidade da prótese.

\section{2 - Outras causas articulares de dor}

Existem causas de dor que provocam grande disfunção cujo diagnóstico é relativamente simples e merecem ser citadas:

a. Patellar clunk syndrome ou síndrome do ressalto patelar: o diagnóstico é caracterizado por um estalido ou ressalto no movimento de flexão entre 30 e 45 graus de flexão. O fenômeno mecânico é provocado por um nódulo fibroso suprapatelar que interfere no deslizamento da patela sobre a tróclea femoral. Esse fenômeno está intimamente associado com o desenho do componente femoral, apresentando incidência de até 3,9\% em próteses do tipo Insall-Burnstein tipo $\mathrm{II}^{(20)}$. Cerca de 50\% dos pacientes evoluem bem apenas com observação ${ }^{(21)}$. Para os demais, o tratamento é a ressecção do nódulo que pode ser feita por via $\operatorname{artroscópica~}^{(22)}$.

b. Irritação da faceta lateral da patela: se o componente patelar é muito pequeno e implantado muito medial e/ou se o osteófito lateral da patela não é ressecado adequadamente, haverá um conflito da faceta lateral da patela com o implante femoral, na região do côndilo lateral que provoca dor no joelho ${ }^{(23)}$. O tratamento deve ser a ressecção do osteófito ou a troca do componente patelar (Figura 9).

c. Disfunção do tendão do poplíteo: o ressalto do tendão do poplíteo sobre o bordo do implante femoral ou sobre um osteófito póstero-lateral pode ser doloroso ${ }^{(24)}$. Durante a cirurgia devemos pesquisar a presença deste fenômeno com os implantes de prova ou mesmo após

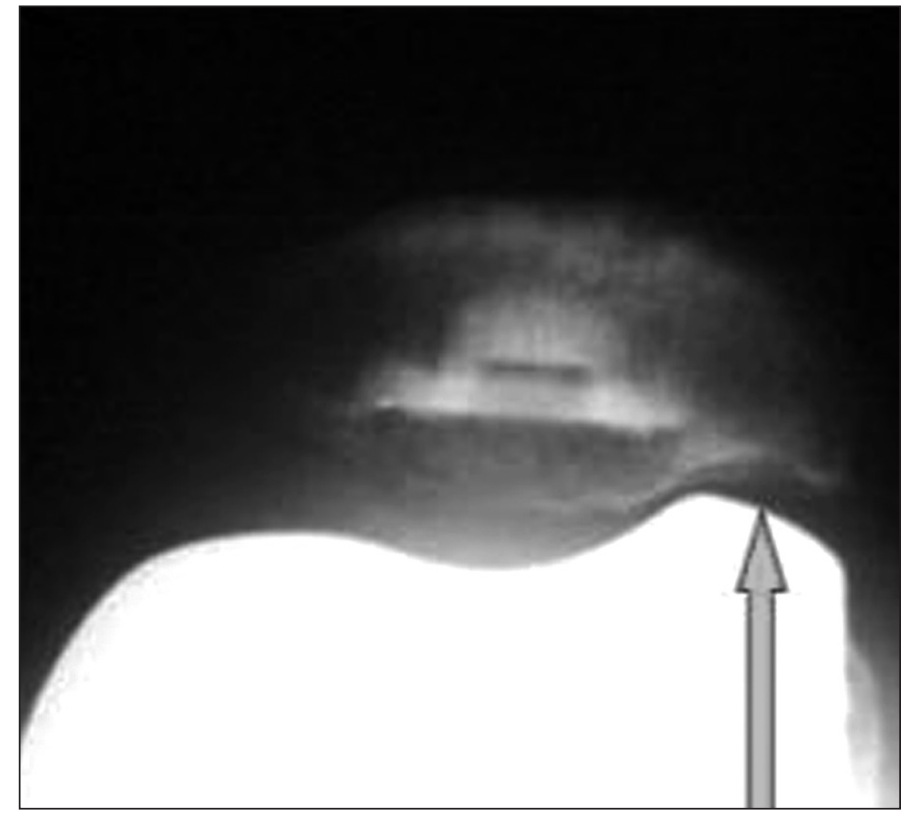

Figura 9 - Irritação da faceta lateral da patela: se o componente patelar é muito pequeno e implantado muito medial e/ou se o osteófito lateral da patela não é ressecado adequadamente, haverá um conflito da faceta lateral da patela com o implante femoral, na região do côndilo lateral que provoca dor no joelho (seta).

a fixação dos componentes. Se estiver presente o ressalto lateral, procurar avaliar as duas situações citadas, corrigindo o tamanho do implante ou ressecando o osteófito.

d. Componente tibial medial saliente: se o componente tibial estiver muito grande e formando uma saliência medial, haverá dor medial (Figura 2). O excesso do componente funciona como um osteófito medial, provocan do dor por distensão do ligamento colateral medial. Para evitar esta complicação, devemos ajustar o tamanho do componente tibial de maneira precisa durante a operação inicial. A única solução após a cirurgia é a troca do componente.

\section{CAUSAS NÃO ARTICULARES DE DOR APÓS ATJ}

As causas não articulares de dor no joelho devem ser consideradas especialmente nos pacientes que revelam que os sintomas atuais são semelhantes aos sintomas pré-operatórios. Devemos investigar doenças neurológicas, tais como neurite periférica provocada por diabetes, doenças do quadril que provocam dor irradiada no joelho, tais como coxartrose, necrose avascular e fratura por insuficiência do osso subcondral da cabeça femoral. A avaliação vascular sempre deve ser realizada nos casos de suspeita de claudicação intermitente. 
Os neuromas cutâneos são mais frequentes do que podemos supor. $\mathrm{O}$ diagnóstico não é difícil, mas exige que o cirurgião considere essa patologia e examine o joelho adequadamente. É importante salientar que a ocorrência de neuromas de cicatriz é mais frequente nos joelhos com múltiplas operações prévias. $\mathrm{O}$ ramo infrapatelar do nervo safeno é o mais afetado nas artroplastias totais do joelho.

Bursites e tendinites são causas não articulares que provocam dor no joelho e devem ser investigadas clinicamente. A palpação cuidadosa do joelho pode revelar estas condições.

Como diagnóstico de exclusão, podemos considerar fatores psicológicos como causa de dor na artroplastia. Entretanto, só devemos considerar essa hipótese após completar toda a rotina da investigação diagnóstica. É importante um bom aconselhamento pré-operatório para que haja um esclarecimento das reais expectativas do paciente e do cirurgião acerca do resultado do procedimento. Mannion et al ${ }^{(25)}$ avaliaram de forma prospectiva 112 pacientes submetidos à artroplastia total do joelho. Após dois anos de seguimento, notou-se que os pacientes subestimaram o tempo de recuperação, que $85 \%$ dos pacientes acreditavam que ficariam completamente sem dor, enquanto isso ocorreu em apenas $43 \%$ dos casos e que $52 \%$ pensavam que não haveria limitação funcional para as atividades usuais, enquanto isso se concretizou em apenas $20 \%$.

\section{CONCLUSÕES}

Joelhos que apresentam dor após a ATJ devem ser abordados de uma maneira sistematizada para se chegar a um diagnóstico preciso. O tratamento só deve ser instituído após o diagnóstico da causa da dor, lembrando que apenas $17 \%$ dos casos com dor de origem desconhecida submetidos à revisão apresentam melhora do seu quadro.

A seguinte sequência sempre deve ser seguida: história, exame físico, avaliação laboratorial e radiológica. Se ao final dessa avaliação o diagnóstico for determinado, o cirurgião está autorizado a instituir o tratamento. Caso contrário, o médico deve observar e repetir periodicamente essa sequência até chegar ao diagnóstico.

Sugerimos ao leitor interessado consultar o artigo de revisão publicado por Mandalia et al, cujas ideias influenciaram e inspiraram a realização deste texto.

\section{REFERÊNCIAS}

1. Brassard MF, Insall JN, Scuderi GR, Faris PM. Complications of Total Knee Arthroplasty. In: Insall JN, Scott WN. Surgery of the knee. Philadelphia: Churchill Livingstone; 2006. p. 1753.

2. Mont MA, Serna FK, Krackow KA, Hungerford DS. Exploration of radiographically normal total knee replacements for unexplained pain. Clin Orthop Relat Res. 1996;(331):216-20.

3. Mandalia V, Eyres K, Schranz P, Toms AD. Evaluation of patients with a painfu total knee replacement. J Bone Joint Surg Br. 2008;90(3):265-71.

4. Dellon AL, Mont MA, Krackow KA, Hungerford DS. Partial denervation for persistent neuroma pain after total knee arthroplasty. Clin Orthop Relat Res. 1995;(316):145-50.

5. Huang TW, Wang CJ, Huang SC. Polyethylene-induced pes anserinus bursitis mimicking an infected total knee arthroplasty: a case report and review of the literature. J Arthroplasty. 2003;18(3):383-6.

6. Pandher DS, Boparai RS, Kapila R. Biceps tendinitis as a cause of acute painful knee after total knee arthroplasty. J Arthroplasty. 2009;24(8):1292.

7. Berger RA, Crossett LS, Jacobs JJ, Rubash HE. Malrotation causing patellofemoral complications after total knee arthroplasty. Clin Orthop Relat Res. 1998;(356):144-53.

8. Malo M, Vince KG. The unstable patella after total knee arthroplasty: etiology prevention, and management. J Am Acad Orthop Surg. 2003;11(5):364-71.

9. Katz MM, Hungerford DS, Krackow KA, Lennox DW. Reflex sympathetic dystrophy as a cause of poor results after total knee arthroplasty. J Arthroplasty 1986;1(2):117-24.

10. Toms AD, Mandalia $V$, Haigh $R$, Hopwood $B$. The management of patients with painful total knee replacement. J Bone Joint Surg Br. 2009;91(2):143-50.

11. Mason JB, Fehring TK, Odum SM, Griffin WL, Nussman DS. The value of white blood cell counts before revision total knee arthroplasty. J Arthroplasty. 2003;18(8):1038-43.

12. Rosenthall L, Lepanto L, Raymond F. Radiophosphate uptake in asymptomatic knee arthroplasty. J Nucl Med. 1987;28(10):1546-9.

13. Alencar PGC. Revisão de artroplastia total de joelho. In: Herbert S, Barros Filho TEP, Xavier R, Pardini Júnior AG, et al. Ortopedia e traumatologia: princípios e

prática. Porto Alegre: Artmed; 2009. p.540-50.

14. Smith SL, Wastie ML, Forster I. Radionuclide bone scintigraphy in the detection of significant complications after total knee joint replacement. Clin Radiol. 2001;56(3):221-4

15. Math KR, Zaidi SF, Petchprapa C. Imaging of the Painful Total Knee Arthroplasty. In: Insall JN, Scott WN. Surgery of the Knee. Philadelphia: Churchill Livingstone; 2006. p. $193-200$

16. Lee J, Robinson G, Finlay K, Friedman L, Winemaker M. Evaluation of the quadriceps tendon, patellar tendon, and collateral ligaments after total knee arthroplasty: appearances in the early postoperative period. Can Assoc Radiol J. 2006;57(5):291-8.

17. Sofka CM, Adler RS, Laskin R.Sonography of polyethylene liners used in total knee arthroplasty. AJR Am J Roentgenol. 2003;180(5):1437-41.

18. Sofka CM. Current applications of advanced cross-sectional imaging techniques in evaluating the painful arthroplasty. Skeletal Radiol. 2007;36(3):183-93.

19. Firestone TP, Eberle RW. Surgical management of symptomatic instability following failed primary total knee replacement. J Bone Joint Surg Am. 2006;88(4):80-4.

20. Maloney WJ, Schmidt R, Sculco TP. Femoral component design and patellar clunk syndrome. Clin Orthop Relat Res. 2003;(410):199-202.

21. Ip D, Ko PS, Lee OB, Wu WC, Lam JJ. Natural history and pathogenesis of the patella clunk syndrome. Arch Orthop Trauma Surg. 2004;124(9):597-602.

22. Dajani KA, Stuart MJ, Dahm DL, Levy BA. Arthroscopic treatment of patellar clunk and synovial hyperplasia after total knee arthroplasty. J Arthroplasty. 2010;25(1):97-103.

23. Doerr TE, Eckhoff DG. Lateral patellar burnishing in total knee arthroplasty following medialization of the patellar button. J Arthroplasty. 1995;10(4):540-2.

24. Allardyce TJ, Scuderi GR, Insall JN. Arthroscopic treatment of popliteus tendon dysfunction following total knee arthroplasty. J Arthroplasty. 1997;12(3):353-5

25. Mannion AF, Kämpfen S, Munzinger U, Kramers-de Quervain I.The role of patient expectations in predicting outcome after total knee arthroplasty. Arthritis Res Ther. 2009;11(5):R139. 